\title{
Altered Traveling Wave Propagation and Reduced Endocochlear Potential Associated with Cochlear Dysplasia in the BETA2/NeuroD1 Null Mouse
}

\author{
Anping Xia ${ }^{1}$, Ann Marie B. Visosky ${ }^{1}$, Jang-Hyeon Cho $^{2}$, Ming-Jer Tsai $^{2}$, Fred A. Pereira ${ }^{1,2,3,4}$, \\ and JOHn S. OGHalai ${ }^{1,4}$ \\ ${ }^{1}$ The Bobby R. Alford Department of Otolaryngology - Head and Neck Surgery, Baylor College of Medicine, One Baylor Plaza, \\ NA102, Houston, TX 77030, USA \\ ${ }^{2}$ Department of Molecular and Cellular Biology, Baylor College of Medicine, Houston, TX 77030, USA \\ ${ }^{3}$ Huffington Center on Aging, Baylor College of Medicine, Houston, TX 77030, USA \\ ${ }^{4}$ Department of Bioengineering, Rice University, Houston, TX 77251, USA
}

Received: 15 February 2007; Accepted: 20 July 2007; Online publication: 15 August 2007

\begin{abstract}
The BETA2/NeuroD1 null mouse has cochlear dysplasia. Its cochlear duct is shorter than normal, there is a lack of spiral ganglion neurons, and there is hair cell disorganization. We measured vertical movements of the tectorial membrane at acoustic frequencies in excised cochleae in response to mechanical stimulation of the stapes using laser doppler vibrometry. While tuning curve sharpness was similar between wild-type, heterozygotes, and null mice in the base, null mutants had broader tuning in the apex. At both the base and the apex, null mice had less phase lag accumulation with increasing stimulus frequency than wild-type or heterozygote mice. In vivo studies demonstrated that the null mouse lacked distortion product otoacoustic emissions, and the cochlear microphonic and endocochlear potential were found to be severely reduced. Electrically evoked otoacoustic emissions could be elicited, although the amplitudes were lower than those of wild-type mice. Cochlear cross-sections revealed an incomplete partition malformation, with fenestrations within the modiolus that connected the cochlear turns. Outer hair cells from null mice demonstrated the normal pattern of prestin expression within their lateral walls and normal FM 1-43 dye entry.
\end{abstract}

Correspondence to: John S. Oghalai • The Bobby R. Alford Department of Otolaryngology - Head and Neck Surgery - Baylor College of Medicine • One Baylor Plaza, NA102, Houston, TX 77030, USA. Telephone: +1-713-7983234; fax: +1-713-7985078; email: jso@bcm.edu
Overall, these data demonstrate that while tonotopicity can exist with cochlear dysplasia, traveling wave propagation is abnormally fast. Additionally, the presence of electrically evoked otoacoustic emissions suggests that outer hair cell reverse transduction is present, although the acoustic response is shaped by the alterations in cochlear mechanics.

Keywords: cochlea, cochlear malformation, cochlear mechanics, incomplete partition, hearing loss, cochlear partition

\section{INTRODUCTION}

Cochlear dysplasia (or malformation) is usually, but not always, associated with hearing loss (Bamiou et al. 1999; Coticchia et al. 2006; Jackler et al. 1987; Schuknecht 1993). While commonly identified clinically during the evaluation of a patient with congenital hearing loss, the effects of dysplasia on cochlear mechanics have not been well defined. In the mammalian cochlea, progressive changes in the mass and stiffness of the basilar membrane determine the resonant frequency map of the cochlea (Geisler 1998). The apex of the cochlea is tuned to low frequencies, and the base of the cochlea is tuned to high frequencies. Sound pressure waves enter the 
cochlea by vibration of the stapes at the oval window and create a traveling wave that propagates up the cochlear duct to maximally stimulate the area of the cochlear partition tuned to that frequency. Frequency tuning is sharpened and vibrations are enhanced by outer hair cells, a process called the cochlear amplifier (Davis 1983; Rhode 1971; Ruggero and Rich 1991). Somatic and stereociliary motility have both been proposed as the basis of cochlear amplification (Brownell et al. 1985; Chan and Hudspeth 2005; Fettiplace and Hackney 2006; Jia and He 2005; Kennedy et al. 2006).

BETA2/NeuroD1 is a basic helix-loop-helix transcription factor initially found to be important in pancreatic and brain development. Together with the Math and Neurogenin subfamilies, they belong to the Drosophila proneural Ath group. The gene was cloned when it was discovered that it upregulates insulin gene expression and was named Beta cell Ebox Transcriptional Activator 2 (Beta2; Naya et al. 1995). The same year, it was independently cloned based on its requirement for neuronal differentiation and named NeuroD (Lee et al. 1995). The transcription factor is now referred to as BETA2/NeuroD1, and it is important in both cell cycle withdrawal and cell differentiation.

While BETA2/NeuroD1 heterozygotes have normal cochlear anatomy, null mice demonstrate substantial cochlear dysplasia (Kim et al. 2001; Liu et al. 2000a). The cochlear duct is shortened, with growth halted at 1.25 turns compared to the normal 1.75 turns (Morsli et al. 1998). However, the tectorial membrane, the stria vascularis, and Reissner's membrane are histologically normal. The most striking finding is an almost complete absence of spiral ganglion neurons. The sensory epithelium within the cochlear partition is present, but there is hair cell misalignment that is presumably the result of defects in migration of neuronal precursors. In particular, some inner hair cells are found within the region of the outer hair cells.

Herein, we assessed the impact of the BETA2/ NeuroD1 null cochlear dysplasia on several aspects of cochlear physiology. Although the cochlear partition could be stimulated to vibrate in a tonotopic manner, traveling wave propagation was abnormal. Our data also suggest that outer hair cells are able to generate force within this dysplastic cochlea.

\section{MATERIALS AND METHODS}

Animals

The study protocol was approved by the Baylor College of Medicine Institutional Animal Care and Use Committee. The BETA2/NeuroD1 transgenic mice were generated and then bred into a $129 \mathrm{SvJ}$ background to reduce the rate of perinatal lethality due to diabetes as described previously (Liu et al. $2000 \mathrm{~b})$. This permitted survival of $60-70 \%$ of the null mutants into adulthood. All mice used in this study were bred from F2 and F3 heterozygotes and were between 4-8 weeks old. The data presented in this manuscript came from studying a total of 74 mice.

\section{Measurement of vertical tectorial membrane movements}

An excised cochlear preparation was used to measure movements of the cochlear partition in response to mechanical vibration of the stapes. Specifically, we measured vertical displacements of a silver-coated bead placed on top of the tectorial membrane. Studies were performed in a standard extracellular solution. This was similar in composition to perilymph, and contained, in mM: $152 \mathrm{NaCl}, 6 \mathrm{KCl}, 1.5$ $\mathrm{CaCl}_{2}, 2$ Na-pyruvate, 10 HEPES, and 10 glucose. The $\mathrm{pH}$ was 7.35 , and the osmolality was $315 \mathrm{mOsm} / \mathrm{kg}$.

While this preparation has not been described before using the mouse cochlea, similar preparations using excised guinea pig and gerbil cochleae have been described (Chan and Hudspeth 2005; Gummer et al. 1996; Mammano and Ashmore 1995; Morioka et al. 1995; Nowotny and Gummer 2006). The temporal bones were harvested after the mouse was killed by cervical disarticulation while under a surgical plane of anesthesia. In standard extracellular solution, the bulla was dissected open and the cochlea exposed under a dissecting microscope (Stemi-2000C, Zeiss, Germany). The incus was carefully disarticulated from the stapes and removed. The cochlea was then glued upright into a chamber (IsoDent, Ellman International, Oceanside, NY). A small section of the otic capsule bone overlying the scala vestibuli was removed with a fine knife. Reissner's membrane was then perforated and the organ of Corti visualized. Care was taken not to touch the tectorial membrane. Roughly 4-5 silver-coated glass beads about $15-25 \mu \mathrm{m}$ in diameter each (Conduct-OFil S3000-S3N, specific gravity $2.5 \mathrm{~g} / \mathrm{cc}$, Potters Industries, Carlstadt, NJ) were carefully dropped onto the tectorial membrane.

The chamber was then moved to our experimental upright microscope (Axioskop 2 FS plus, Zeiss) and fixed securely in place. By illuminating the cochlea from below, we could visualize the organ of Corti and the hair cells using a $40 \times$ water immersion objective (Achroplan, NA=0.8, Zeiss). A 4-cm length of tungsten wire (0.005 in. diameter, A-M Systems) glued to a piezoelectric actuator (PA8-12, piezosystem jena) was advanced through the external solution with a micromanipulator until it gently contacted the stapes capit- 
ulum. A laser doppler vibrometer (OFV-5000, Polytech PI) attached to the trinocular port of the microscope was focused on the bead to measure vertical movements of the tectorial membrane. The velocity output was low-pass filtered at $100 \mathrm{kHz}$ and digitized at $100 \mathrm{kHz}$ for offline analysis. The magnitude and phase responses between $1-40 \mathrm{kHz}$ were calculated by FFT analysis and referenced to stapes motion, measured in a similar fashion using a bead placed on the anterior crus. The data were smoothed using a three-point boxcar filter, and the baseline of the phase response was zeroed at the low-frequency baseline.

When designing this setup, we verified that the preparation was securely fixed by measuring the vertical velocity of a bead placed on the osseous spiral lamina near the site of the tectorial membrane bead. In all five preparations examined, we found that the velocity was at least $30 \mathrm{~dB}$ less than that of the tectorial membrane over the frequency range of $1-40 \mathrm{kHz}$. This suggests that the tectorial membrane response was not significantly contaminated by movement of the entire preparation.

\section{In vivo experiments}

Procedures performed on anesthetized mice included measuring the auditory evoked brainstem response (ABR), distortion product otoacoustic emissions (DPOAEs), the cochlear microphonic (CM), the endolymphatic potential (EP), and electrically evoked otoacoustic emissions (EEOAEs). Mice of either sex were anesthetized using ketamine $(100 \mathrm{mg} / \mathrm{kg})$ and xylazine $(5 \mathrm{mg} / \mathrm{kg})$. Supplemental doses of anesthesia were administered to maintain areflexia to paw pinch.

Sine wave stimuli were generated digitally using MATLAB (Release 13, The Mathworks, Natick, MA), converted to analog signals using a digital-to-analog converter running at $200 \mathrm{kHz}$, and then attenuated to the appropriate intensity according to our experimental design (RP2 and PA5, Tucker-Davis Technologies; Oghalai 2004). To generate the acoustic stimuli, two different speaker systems were used: high frequency piezoelectric speakers for the ABR and DPOAE measurements (EC1, Tucker-Davis Technologies) and a supertweeter (Radio Shack) for the CM. The speakers were connected to an earbar inserted into the ear canal and calibrated from 4 to $95 \mathrm{kHz}$ by a probe-tip microphone (type 8192, NEXUS conditioning amplifier, Bruel and Kjar, Denmark) inserted through the earbar. The tip of the microphone was within $3 \mathrm{~mm}$ of the tympanic membrane.

\section{ABR measurements}

The ABR signal was measured with a bioamplifier (DB4, Tucker-Davis Technologies) from a needle electrode positioned at the ventral surface of the tympanic bulla referenced to an electrode placed at the vertex of the skull, as previously described (Wenzel et al. 2006). A ground electrode was placed in the hind leg. The stimulus was a $5 \mathrm{~ms}$ sine wave tone pip of alternating polarity with $\cos ^{2}$ envelope rise and fall times of $0.5 \mathrm{~ms}$ and a repetition time of $50 \mathrm{~ms}$. The stimulus intensity ranged from 10 to 80 $\mathrm{dB}$ SPL in $10 \mathrm{~dB}$ steps. The frequency range studied was 4 to $80 \mathrm{kHz}$. Two hundred and fifty ABR responses were sampled at $25 \mathrm{kHz}$ over the $50 \mathrm{~ms}$ repetition time and averaged. Thresholds were calculated offline. At each frequency, the peak-to-peak voltage of the ABR waveform was measured, and the data interpolated over the range of stimulus intensities. The threshold was determined to be when the ABR was four standard deviations above the noise floor. If no ABR response was detected even at our equipment limits of $80 \mathrm{~dB}$ SPL, we arbitrarily defined the threshold to be $80 \mathrm{~dB}$.

\section{DPOAE measurements}

DPOAEs were measured as previously described (Paylor et al. 2006). Briefly, the stimuli for eliciting DPOAEs were two sine wave tones of differing frequencies $(F 2=1.2 \times F 1)$ of 1 -s duration with $\mathrm{F} 2$ ranging from 4 to $43 \mathrm{kHz}$. The two tones were presented at identical intensities, which ranged from 20-80 dB SPL in $10 \mathrm{~dB}$ increments. The acoustic signal picked up by the microphone in the earbar was digitized at $200 \mathrm{kHz}$ and the magnitude of the $2 \times F 1-F 2$ distortion product determined by FFT. The surrounding noise floor was also calculated by averaging 20 adjacent frequency bins around the distortion product frequency. DPOAE thresholds were calculated offline by interpolating the data and identifying when the signal was $>-5 \mathrm{~dB}$ SPL and greater than two standard deviations above the noise floor. If no DPOAE response was detected even at our equipment limits of $80 \mathrm{~dB}$ SPL, we arbitrarily defined the threshold to be $80 \mathrm{~dB}$.

\section{CM measurements}

The CM is a field potential that reflects the summation of hair cell transduction currents primarily from outer hair cells of the basal turn of the cochlea (Cheatham and Dallos 1982; Cheatham and Dallos 1997; Dallos 1975; Patuzzi and Moleirinho 1998; Patuzzi et al. 1989). After rigidly securing the mouse in a head holder, a ventral incision was made. This was extended dorsally to the scalp, and the pinna was resected. The bulla was carefully opened medial to the tympanic annulus to expose the round window. The stapedial artery was preserved. The earbar was 
then inserted into the ear canal and secured. The CM was measured from the ball-ended tip of a Tefloncoated silver wire (0.003 in. diameter, A-M Systems, Carlsborg, WA) advanced onto the round window membrane with a micromanipulator. The signal was referenced to a silver wire inserted under the skin near the vertex of the skull. The ground electrode was placed in the hind leg. A bioamplifier was used (DB4, Tucker Davis Technologies) to amplify the signals. The signal was amplified 100 times and no filtering was used. However, the bioamplifier system does not pass DC signals (corner frequency $<20 \mathrm{~Hz}$ ). Additionally, it has a flat frequency response until its innate corner frequency of about $22 \mathrm{kHz}$.

The stimulus was a $30 \mathrm{~ms} 6 \mathrm{kHz}$ tone, repeated every $1 \mathrm{~s}$. Its intensity ranged from 35-90 dB SPL. By measuring the speaker output with the probe tip microphone in the earbar, FFT analysis demonstrated that all stimulus harmonics and noise at all other frequencies were at least $50 \mathrm{~dB}$ below the primary signal at all stimulus intensities. The CM signal measured by the bioamplifier was digitized at $200 \mathrm{kHz}$, and the magnitude of the response at $6 \mathrm{kHz}$ determined by FFT.

\section{EP measurements}

After opening the tympanic bulla, the cochlea was backlit using a fiberoptic cable to highlight the region of the spiral ligament. The bone overlying the basal turn was thinned with a microknife very close to the stapedial artery to expose the spiral ligament. A glass micropipette pulled to a tip diameter of about $1 \mu \mathrm{m}$ filled with $150 \mathrm{mM} \mathrm{KCl}$ was advanced up to the spiral ligament with a micromanipulator. The voltage was measured every $1 \mathrm{~s}$ referenced to a silver wire placed under the skin near the vertex of the skull (Axoclamp-2, Axon Instruments). The baseline bias voltage was compensated for by determining the zero-current potential of the extra-cochlear fluids outside of the spiral ligament, before entering scala media. After entering the endolymphatic space, the EP was recorded until the measurement stabilized (usually about $5-10 \mathrm{~s}$ ). Then, the micropipette was withdrawn from the cochlea and the voltage of the extra-cochlear fluids remeasured to verify that no baseline drift occurred.

\section{EEOAE measurements}

EEOAEs were measured by injecting a constant current sine wave stimulus into the cochlea and measuring the acoustic response by a microphone in the ear canal (Hubbard and Mountain 1990; Mountain and Hubbard 1989; Nuttall et al. 2001; Ren and Nuttall 1995, 2000; Xue et al. 1993). The surgical preparation was similar to that used for measuring the
CM. However, the stimulus was a $212 \mu \mathrm{A}$ rms sine wave (Linear Stimulus Isolator, WPI, Sarasota, FL) that ranged from 4-40 kHz. The current was passed through the cochlea via a ball-ended Teflon-coated silver wire placed on the round window membrane. The actual current delivered was verified by measuring the voltage drop across a $1 \mathrm{k} \Omega$ resister placed in series. The ground return was a silver wire inserted under the skin near the vertex of the scalp. The acoustic response was measured by the microphone in the earbar and digitized with a sampling rate of $100 \mathrm{kHz}$. The magnitude of the response at the stimulus frequency was determined by FFT, and the surrounding 20 frequency bins were averaged to calculate the noise floor.

\section{Histology}

Cochleae were isolated and fixed in $4 \%$ paraformaldehyde overnight. They were then placed in a $0.12 \mathrm{M}$ EDTA for 3-7 days, dehydrated in ethanol, and embedded in paraffin. Serial paraffin sections $(7 \mu \mathrm{m})$ were cut. The hematoxylin and eosin staining procedures have been described previously (Liu et al. 2000a). For immunofluorescence studies, the sections were deparaffinized and washed with phosphate buffered saline containing $0.1 \%$ Triton X-100 (PBST) for $1 \mathrm{~h}$. The sections were then blocked for $1 \mathrm{~h}$ in normal serum at room temperature and incubated with the primary antibody, polyclonal goat antiprestin diluted 1:400 (Santa Cruz Biotechnology, USA), overnight at $4^{\circ} \mathrm{C}$ in a humidified chamber. Sections were washed three times with PBST and then incubated with the secondary antibody, Alexa Fluor 594 mouse anti-goat IgG diluted 1:500 (Molecular Probes/Invitrogen), at room temperature for 1 h. After washing with PBST again, the sections were covered with fluorescence mounting medium and nail polish (Biomeda gel/mount, Foster City, CA) and imaged using an epi-fluorescence microscope (Axioplan 2, Zeiss).

\section{FM 1-43 dye application}

FM 1-43 dye (Molecular Probes/Invitrogen, USA) was diluted to $2.5 \mu \mathrm{M}$ in standard extracellular solution. For certain experiments, $100 \mu \mathrm{M}$ streptomycin sulfate (S-6501, Sigma-Aldrich, St. Louis, MO) was also included. The dye was applied to the excised cochlear preparation for 20 s. FM 1-43 dye quickly enters hair cells through non-specific cation channels (Meyers et al. 2003). The application time was short to minimize signal contamination by dye entry through apical endocytosis (Gale et al. 2001; Griesinger et al. 2002; Griesinger et al. 2004; Griesinger et al. 2005; Kaneko et al. 2006; Meyers et al. 2003). The dye was 
then rinsed away under constant perfusion for another 20 s. FM 1-43 fluorescence within the organ of Corti was visualized using the $40 \times$ water immersion objective using a mercury arc lamp and a filter set (XF21, Omega Optical, Brattleboro, VT). Grey scale images were captured using a digital camera attached to the trinocular port (A101, Basler, Germany). Images were taken immediately following washout.

\section{Statistical analysis}

Data were analyzed with SPSS (11.0 for Windows) and plotted with SigmaPlot (9.0, Systat Software). Statistical significance was assessed using the Student's non-paired two-tailed $t$ test. $P$ values $<0.05$ were considered statistically significant. All presented values are mean \pm SEM.

\section{RESULTS}

\section{Measurement of tectorial membrane motion}

To assess the vibratory characteristics of the cochlear partition, the velocity of a reflective bead placed on top of the tectorial membrane was measured in an excised cochlear preparation (Fig. 1a-c). This purely measures passive cochlear mechanics, and so nonlinearities associated with function of the cochlear amplifier are not assessed. Movements of the cochlear partition were studied at two different locations. Measures in the second turn (apex) were made about 1.5 turns away from the stapes and measures in the first turn (base) were made about 0.5 turns away from the stapes. The piezoelectric actuator mechanically stimulated the stapes at a level approximating $80-100 \mathrm{~dB}$ SPL, and the frequency of the stimulus was varied from either $1-40 \mathrm{kHz}$ (for measurements in the apex) or 4-40 kHz (for measurements in the base) in 40 logarithmically spaced steps. For every preparation, the velocity of the stapes was measured by placing a bead on it, and this was used to normalize the tectorial membrane response data.

Representative raw velocity magnitude data from the apex of a wild-type mouse (Fig. 1d) and from the base of a heterozygote mouse (Fig. 1g) are presented. The resonant frequencies were about 6 and $22 \mathrm{kHz}$, respectively. Stapes velocity magnitudes for each preparation are also shown and demonstrated resonances at about 28 and $24 \mathrm{kHz}$, respectively. This reflects the innate resonance of the loaded piezoelectric actuator. Both the tectorial membrane and the stapes responses were $>20 \mathrm{~dB}$ greater than the noise floor plus three standard deviations.

To compensate for frequency dependent variations of the stimulus amplitude, the magnitude of the tectorial membrane velocity was divided by the magnitude of the stapes velocity. This gives the unitless response ratios (Fig. 1e and h). To compensate for frequency-dependent variations in the phase of the stimulus, the phase of the stapes was subtracted from that of the tectorial membrane (Fig. If and i). This procedure was performed individually for every cochlea studied so as to minimize frequency-dependent contamination of the tectorial membrane responses by the stimulus resonance.

\section{Comparison of the magnitude of tectorial membrane motion}

Movements at the apex and at the base were then compared between the genotypes. Representative examples of velocity magnitude plots are shown (Fig. 2a-c). For each tuning curve, the resonant frequency was identified as the frequency at the magnitude peak. For all three genotypes, the cochlear partition was tuned to higher resonant frequencies at the base than at the apex. At the apex, the resonant frequencies ranged between 4.6 and $10.2 \mathrm{kHz}$ for all 25 tuning curves measured among all three genotypes. Because cochleae from null mice have only 1.25 turns, the apical measures were made at just over 1 turn away from the stapes (rather than at 1.5 turns away from the stapes in controls). Thus, the average resonant frequencies of wild-type and heterozygous mice were lower than that of null mice (wild-type: $5.2 \pm 0.2 \mathrm{kHz}, n=11$; heterozygous: $5.6 \pm 0.4 \mathrm{kHz}, n=9$; null: $8.8 \pm 1.1 \mathrm{kHz}, n=5$; $p<0.005)$.

At the base, the resonant frequencies ranged between 14.6 and $26.4 \mathrm{kHz}$ for all 23 tuning curves measured among the three genotypes. The average resonant frequencies of wild-type and heterozygous mice were not statistically different from that of the null mice (wild-type: $18.8 \pm 0.8 \mathrm{kHz}, n=10$; heterozygous: $23.9 \pm 1.1 \mathrm{kHz}, n=5$; null: $16.6 \pm 1.4 \mathrm{kHz}, n=8$; $p>0.1)$. Overall, the resonant frequency values measured were within the range of what would be expected according to the mouse place-frequency map with no cochlear amplifier present, causing the normal frequency of resonance to drop by about $0.5-$ 1 octave (Cody and Johnstone 1980; Liberman 1982; Muller et al. 2005; Ou et al. 2000).

Tuning curves for each genotype were then averaged after normalizing them for resonance frequency and peak magnitude (Fig. 3a and b). Q10dB values were calculated to assess the sharpness of tuning. This was done using the bandwidth $10 \mathrm{~dB}$ down from the peak magnitude for each tuning curve. At the apex, null mice had broader tuning than wild-type and heterozygous mice (wild-type: $0.94 \pm 0.03$; heterozygous: $0.97 \pm 0.02$; null: $0.68 \pm 0.07$; $p<0.001)$. At the base, all three genotypes had similar 

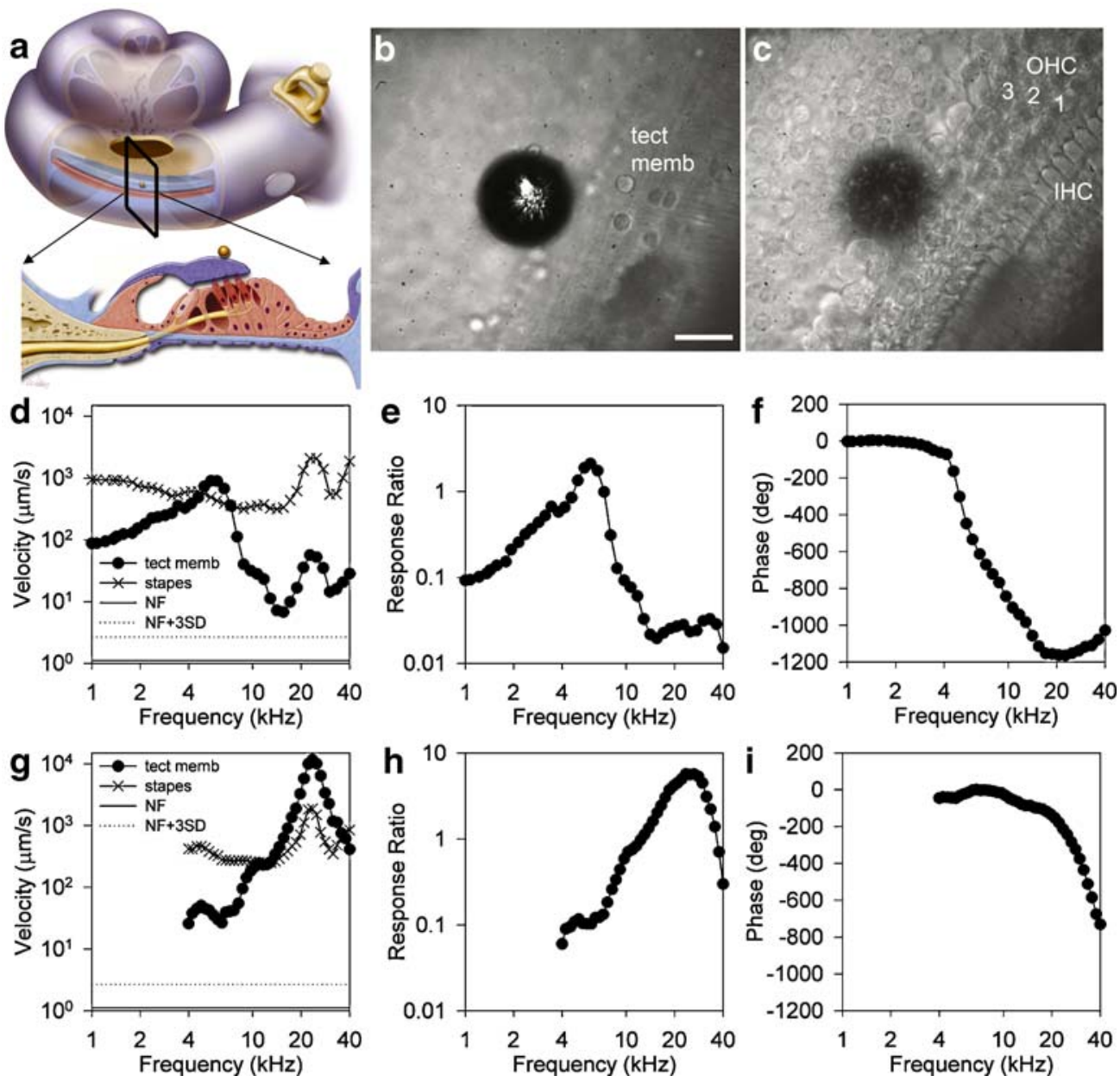

FIG. 1. Method for measuring vertical movements of the mouse tectorial membrane. Data from wild-type mice cochleae are shown in these examples. a Top - an opening was made over the scala vestibuli in an excised cochlea and a silver-coated glass bead was placed on top of the tectorial membrane. Another bead (not shown) was placed on the stapes to measure the velocity of the stimulus. Bottom - cross-section of the organ of Corti illustrating the bead placement on top of the tectorial membrane. $\mathbf{b}$ View through the microscope demonstrating the laser reflecting off of the bead. This bead is lying on the lateral edge of the tectorial membrane (tect memb). Scale bar is $25 \mu \mathrm{m}$. c Focusing deeper into the specimen revealed the inner hair cell region $(I H C)$ and the three rows of outer hair cells $(\mathrm{OHC}$ ). The shadow of the bead can be noted. $\mathbf{d}$ In this example from the cochlear apex, tectorial membrane velocity demonstrated a resonant frequency around $6 \mathrm{kHz}$. The stapes velocity was also measured in every preparation and demonstrated

tuning curve sharpness (wild-type: $1.34 \pm 0.10$; heterozygous: $1.21 \pm 0.10$; null: $1.15 \pm 0.09 ; p>0.1)$.

\section{Comparison of the phase of tectorial membrane motion}

Phase responses measured at the same time as the previously described magnitude responses are shown for all three genotypes at the apex and at the base (Fig. 2d-f). Both wild-type and heterozygous mice demonstrated phase lag accumulations of $>600^{\circ}$ a resonance corresponding to that of the loaded piezoelectric actuator, in this case around $28 \mathrm{kHz}$. Both tectorial membrane velocity and stapes velocity were greater than the average noise floor (NF) and three standard deviations above the noise floor $(N F+3 S D)$. e The unitless response ratio was obtained by dividing tectorial membrane velocity by stapes velocity. $\mathbf{f}$ The phase of the tectorial membrane, after subtracting the phase of the stapes, shows progressive phase lag accumulation. g An example from the cochlear base. In this case, the tectorial membrane velocity demonstrated a resonance at about the same frequency as the actuator. Nevertheless, the response characteristics of the tectorial membrane and stapes velocity magnitudes are substantially different. $\mathbf{h}$ Calculating the response ratio removed the effect of the actuator from the tectorial membrane response. $\mathbf{i}$ The phase of the tectorial membrane response after subtracting the stapes response.

above the resonant frequency at both the base and the apex. In contrast, at the apex, only minimal phase lag accumulation was found in null mice, typically $<250^{\circ}$. At the base of the null cochlea, larger phase lag accumulations were present, although they still did not reach that of wild-type or heterozygote mice. The differences in phase between the genotypes was quantified using averaged, normalized data (Fig. 3c and d). There was significantly less phase lag accumulation in null mice compared to wild-type or heterozygous mice $(p<0.05$ for nearly every tested 

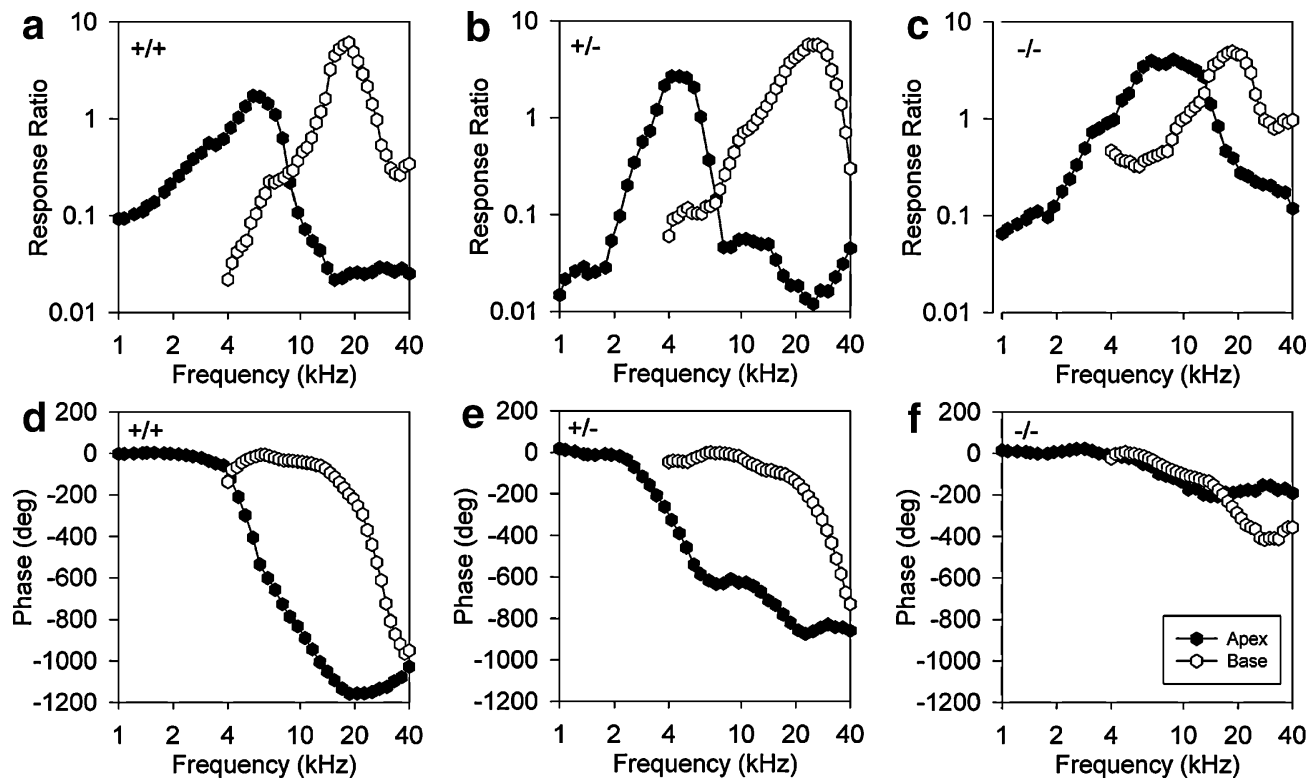

FIG. 2. Representative examples of tectorial membrane movement from six different cochleae. a-c Magnitude plots of the response ratio for all three genotypes. At the apex, the bandwidth of the tuning curve in the null $(-\digamma)$ mouse is broader than that found in wild-type $(+/+)$ or heterozygous $(+/)$ mice, but they are all similar at

frequency above resonance). This effect was larger in the apex than in the base.

\section{In vivo electrophysiology}

Both wild-type and heterozygous mice were found to have normal ABR thresholds (Fig. 4a). The ABR threshold for these groups was lowest at $16.2 \mathrm{kHz}$ and found to be approximately $20 \mathrm{~dB}$ SPL. The only statistically significant difference between the wildtype and heterozygous mice was at $80 \mathrm{kHz}$ with a difference of $6.9 \mathrm{~dB}$, which likely represents random variance. Thus, these data indicate that heterozygous mice have normal auditory thresholds, and further support our findings in the excised cochleae that the vibratory characteristics of the cochlear partition of wild-type and heterozygous mice are similar.

As previously reported, no ABRs could be detected to equipment limits in null mice (Kim et al. 2001; Liu et al. 2000a). This was found across the frequency spectrum of 4-80 kHz, and the differences from wildtype and heterozygous mice were statistically significant at every frequency $(p<0.001)$. These results are not surprising given the lack of spiral ganglion cells.

DPOAE thresholds were also measured for each genotype and there were similar thresholds between wild-type and heterozygous mice (Fig. 4b). No statistically significant differences between the thresholds of wild-type and heterozygous mice were found at any frequency $(p>0.1)$. Null mice lacked DPOAEs at all frequencies to equipment limits, and the the base. $\mathbf{d}-\mathbf{f}$ Simultaneously acquired phase data demonstrate large, progressive phase lag accumulations in wild-type and heterozygous mice with increasing stimulus frequency. A reduced phase lag accumulation was found in the null mouse.

differences from wild-type and heterozygous mice were statistically significant between $10-36 \mathrm{kHz}$ $(p<0.01)$.

Next, the amplitude of the cochlear microphonic at $6 \mathrm{kHz}$ was measured at stimulus intensities ranging from 35-90 dB SPL (Fig. 4c). Normal responses were found in wild-type mice, with the compound action potential dominating the signal at the onset (see raw data inset). Louder intensity stimuli generated larger cochlear microphonic responses that saturated at stimuli $>75 \mathrm{~dB}$ SPL. There were only minimal responses in null mice. The slight response measured at 80-90 dB remained below threshold (three standard deviations above the noise floor). All cochlear microphonic responses in null mice were statistically less than the responses in wild-type mice at the same stimulus intensity $(p<0.001)$.

Wild-type and heterozygous mice had normal endocochlear potentials (wild-type: $93.2 \pm 3.2 \mathrm{mV}$, $n=5$; heterozygous: $98.5 \pm 2.6 \mathrm{mV}, n=6$; Fig. $4 \mathrm{~d}$ ). No statistical difference was found between these two groups of mice $(p>0.1)$. In contrast, null mice had almost no endocochlear potential $(2.0 \pm 1.0 \mathrm{mV}$, range: $0-6 \mathrm{mV}, n=6$ ), which was statistically different from those of wild-type and heterozygous mice $(p<0.001)$.

Lastly, EEOAEs were measured in both wild-type and null mice. Current injected into the cochlea creates a voltage drop across outer hair cells that simulates a receptor potential, leading to force generation that can displace the cochlear partition 

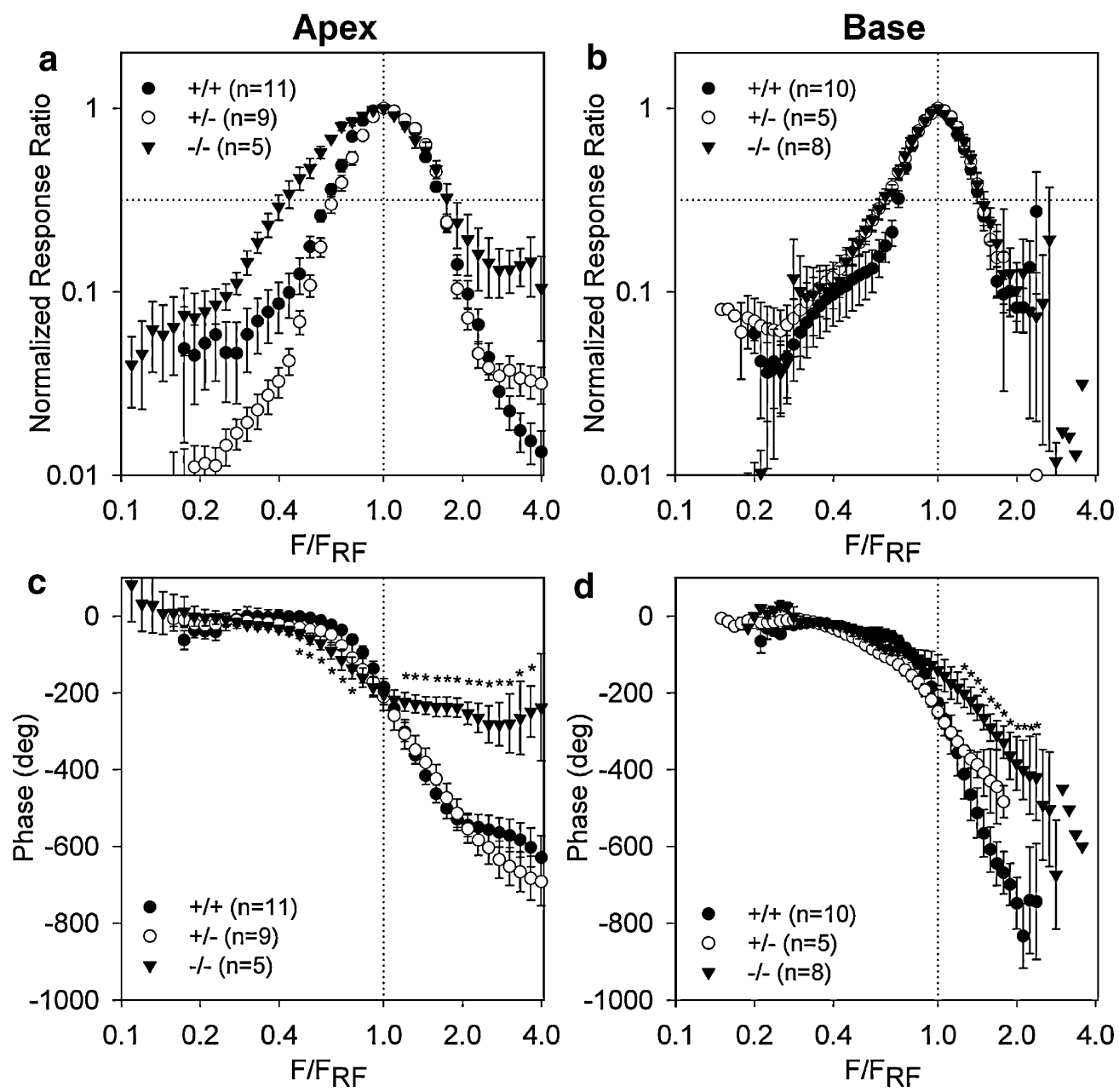

FIG. 3. Averaged tectorial membrane movement, after normalizing to resonant frequency $(R F)$ and peak response ratio. a At the cochlear apex, the sharpness of tuning curve magnitudes were similar in the wild-type $(+/+)$ and heterozygous $(+/)$ mice, but were broader in null $(-/)$ mice. b At the base, the tuning curves for all three genotypes were of similar sharpness. c At the apex, the phase

and be measured as an acoustic emission in the ear canal (Gummer et al. 2002; Hubbard and Mountain 1990; Mammano and Ashmore 1993; Mountain and Hubbard 1989; Nuttall et al. 2001; Ren and Nuttall 1995, 2000). Example raw data tracings using an $8.144 \mathrm{kHz}$ current stimulus injected into a wild-type cochlea are shown (Fig. 5a). During the time of the stimulus (bottom trace), a response was measured with the microphone (top trace). After surgical removal of the tympanic membrane to block sound propagation, no responses above the noise floor could be measured (middle trace). This argues against artifactual contamination of the response from electrical coupling between the current source and the microphone.

A representative example of the response from the same mouse and from a null mouse using current stimuli ranging from 1 to $40 \mathrm{kHz}$ is shown in (Fig. 5b). There were emissions across the entire frequency

responses were similar for wild-type and heterozygous mice, but there was a significantly reduced phase lag accumulation in null mice. d At the base, the phase lag accumulation of null mice was also less than that of wild-type and heterozygous mice, but the difference was not as large as that found at the apex. Statistical significance at each frequency is represented by an asterisk.

spectrum, and the characteristic EEOAE fine structure of multiple peaks and valleys in the responses were noted (Ren and Nuttall 2000). Removal of the tympanic membrane reduced the responses to the level of the noise floor across the frequency spectrum. Across the measured frequency spectrum, null mice were found to have generally lower responses than wild-type mice (Fig. 5c). The differences were larger and tended to be statistically significant at frequencies $>10 \mathrm{kHz}$ $(p<0.05)$.

\section{Histology}

Serial sections through wild-type $(n=3)$ and null $(n=3)$ cochleae oriented along their central axis were evaluated. After staining with hematoxylin and eosin, every section was examined in sequence. A detailed histological description of the development of the 

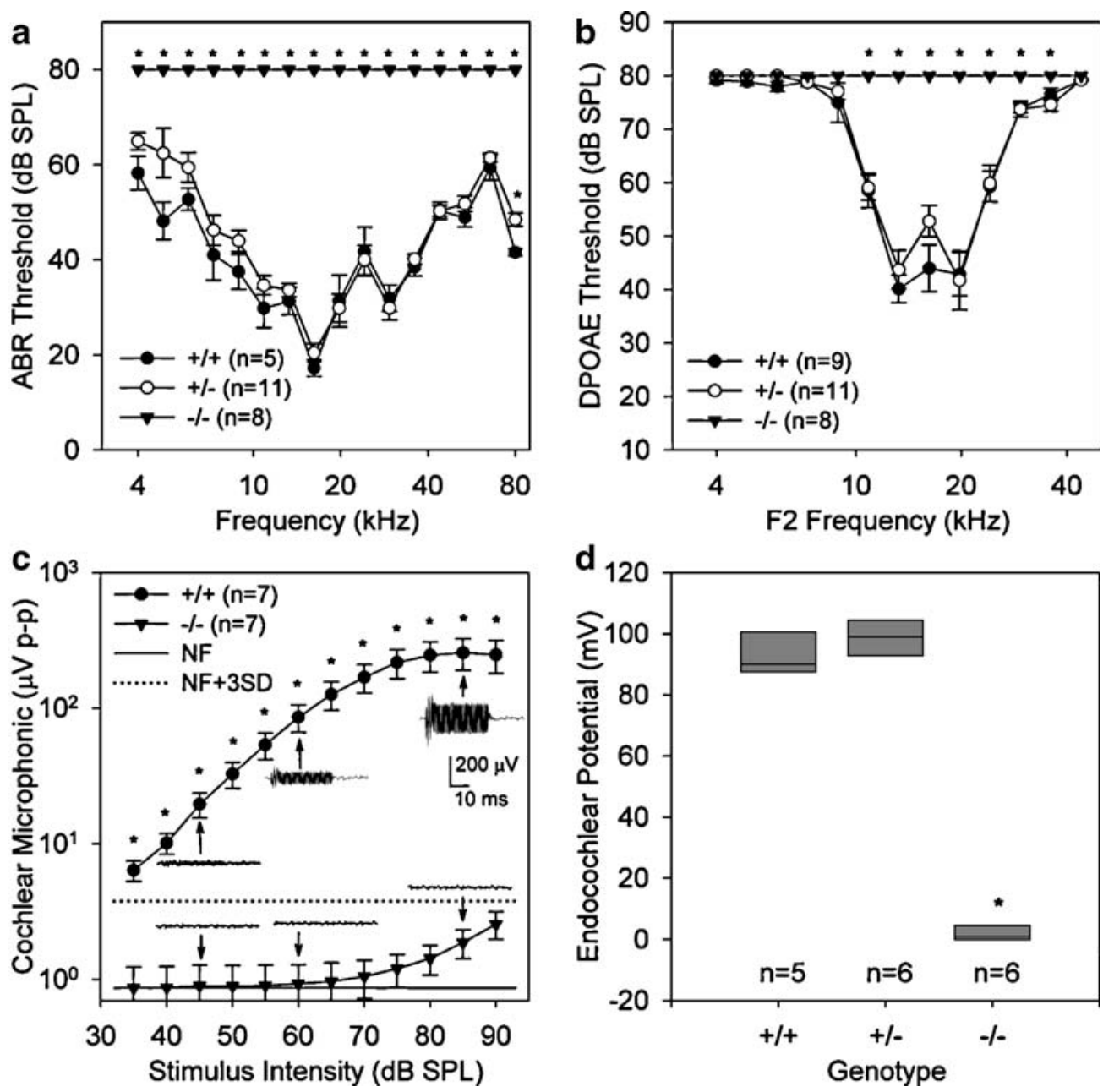

FIG. 4. Electrophysiological responses measured in vivo. a $A B R$ thresholds for wild-type $(+/+)$ and heterozygous $(+/)$ mice were similar, while null $(-\digamma)$ mice had no ABR signal to equipment limits (80 dB SPL). b DPOAE thresholds for wild-type and heterozygous mice were similar, while null mice had no DPOAEs to equipment limits (80 dB SPL). c Cochlear microphonic responses measured at 6 $\mathrm{kHz}$ demonstrated a normal pattern of saturating amplitude growth

BETA2/NeuroD1 null cochlea has been reported previously (Liu et al. 2000a). Additionally, histological studies on heterozygous mice were not performed as their cochleae have already been shown to be similar to cochleae of wild-type mice.

For the purposes of this study, we focused our attention on the modiolus. Light microscopy confirmed the near-complete lack of spiral ganglion cells or auditory nerve fibers in null mice as has been previously reported (Fig. 6; Kim et al. 2001; Liu et al. 2000a). The bone of the modiolus was deficient so that there were large channels within the central core of the cochlea that connected the cochlear turns. Bone was present within the osseous spiral lamina, which supported the spiral limbus. This bone was connected to the rest of the temporal bone at the base of the cochlea (not visible in this section taken

with increasing stimulus intensity in wild-type mice. In contrast, null mice demonstrated only a slight response at the highest stimulus levels. The inset tracings show representative raw data at the indicated stimulus levels. $\mathbf{d}$ The endocochlear potential of wild-type and heterozygous mice were normal, while there was little to no endocochlear potential in null mice. Statistical significance is represented by an asterisk.

through the center of the cochlea). Importantly, there was a normal shape of the scala media, and no gross connections between the perilymph and endolymph compartments were visualized. To summarize, while the scala media appeared grossly normal, the bony partition between the cochlear turns was incomplete and contained large fenestrations.

Additionally, prestin protein expression was assessed by immunolabeling paraffin-fixed sections take from adult mice. Prestin expression was similar in both wildtype and null mice and appeared to be restricted to the lateral wall region of the outer hair cells (Fig. 7).

FM 1-43 dye entry

The ability of FM 1-43 dye to enter hair cells in cochleae excised from BETA2/NeuroD1 mice was 

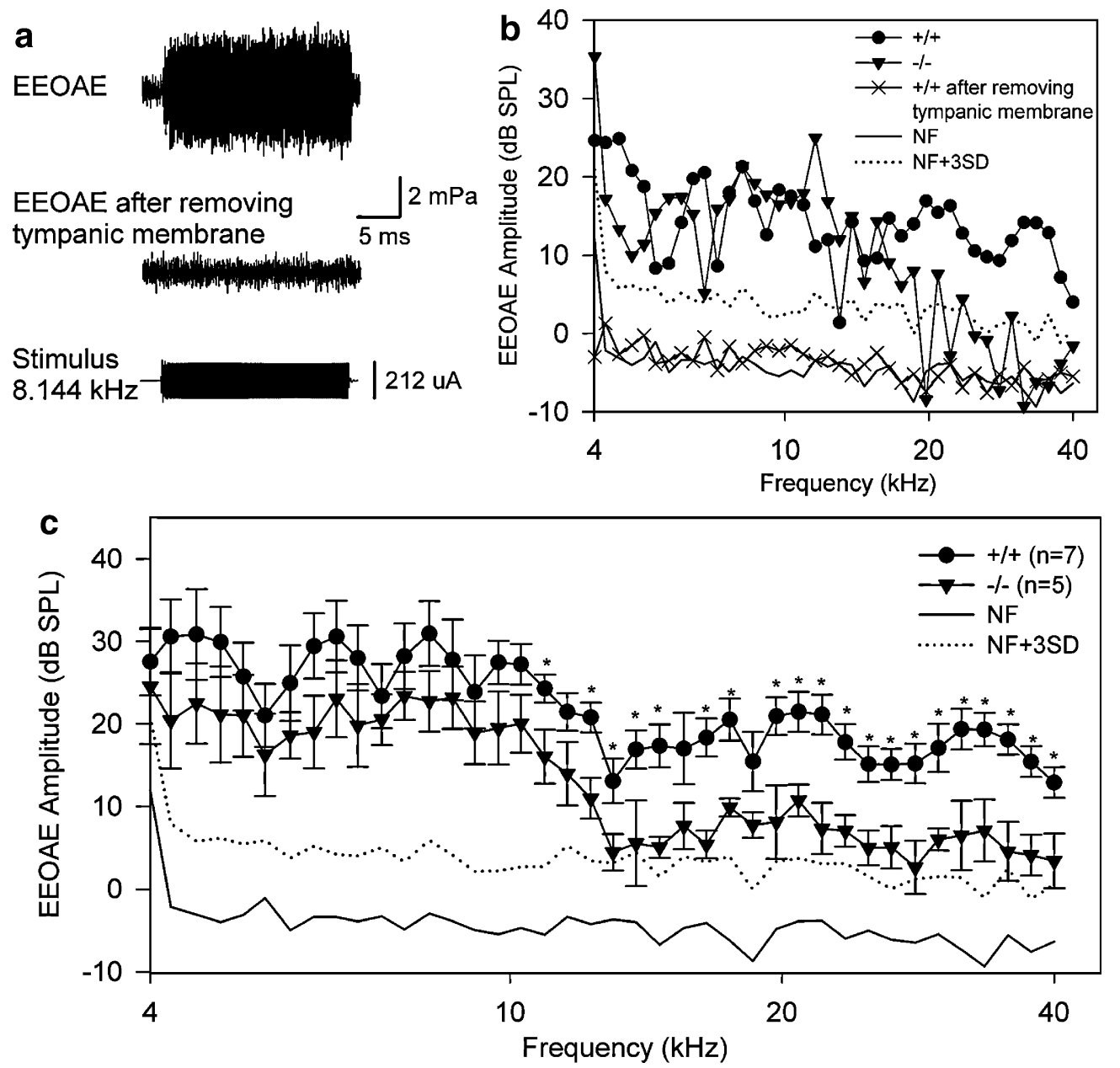

FIG. 5. Electrically evoked otoacoustic emissions (EEOAEs). a Raw data from a wild-type mouse demonstrating the acoustic emission measured by the microphone in the ear canal (top trace) and the $8.144 \mathrm{kHz}$ current stimulus applied to the round window (bottom trace). The lack of an acoustic emission after the tympanic membrane was removed (middle trace) indicates that the microphone was not measuring electrical artifact, but a true sound emission. b Representative EEOAE data from wild-type $(+/+)$ and

tested. This was done both to visualize the disorganization of the hair cells within the epithelium of the mutant and to assess whether the dye could enter hair cells through mechanoelectrical transducer channels similarly in mutants and in controls. In the wild-type organ of Corti, fluorescence of inner and outer hair cell stereocilia was noted (Fig. 8a). To verify that this fluorescence represented dye inside the cell, continuous and extensive wash out of the dye was performed for another $90 \mathrm{~s}$ and a repeat image was taken (Fig. 8a, inset). Dye could be noted within the intracellular compartment of both inner and outer hair cells. In another experiment, the transduction channel-blocker streptomycin was applied to a preparation of the wild-type organ of Corti before and during the application of FM 1-43 dye (Fig. 8b). In this case, the stereocilia did not demonstrate fluorescence. Heterozygote and null null (-/-) mice recorded at frequencies between $4-40 \mathrm{kHz}$. Removing the tympanic membrane reduced the measured response to the level of the noise floor. c Averaged data demonstrate that both wild-type $(+/+)$ and null $(-/-)$ mice can produce EEOAEs. However above $12 \mathrm{kHz}$, the responses of the null mice were less than those of the wild-type mice. Statistical significance is represented by an asterisk.

mice demonstrated FM1-43 dye entry into inner and outer hair cells in a similar fashion to that found in wild-type mice (Fig. 8c and d). Hair cell disorganization and missing hair cells were noted within the null cochlea as previously reported (Kim et al. 2001; Liu et al. 2000a).

\section{DISCUSSION}

The BETA2/NeuroD1 null mouse has altered cochlear biomechanics

BETA2/NeuroD1 null mice have a severe cochlear dysplasia. One feature is that there are large connections between the perilymphatic chambers through the central core of the cochlea. This malformation is associated with broader tuning than normal at the cochlear apex and a reduced accumu- 


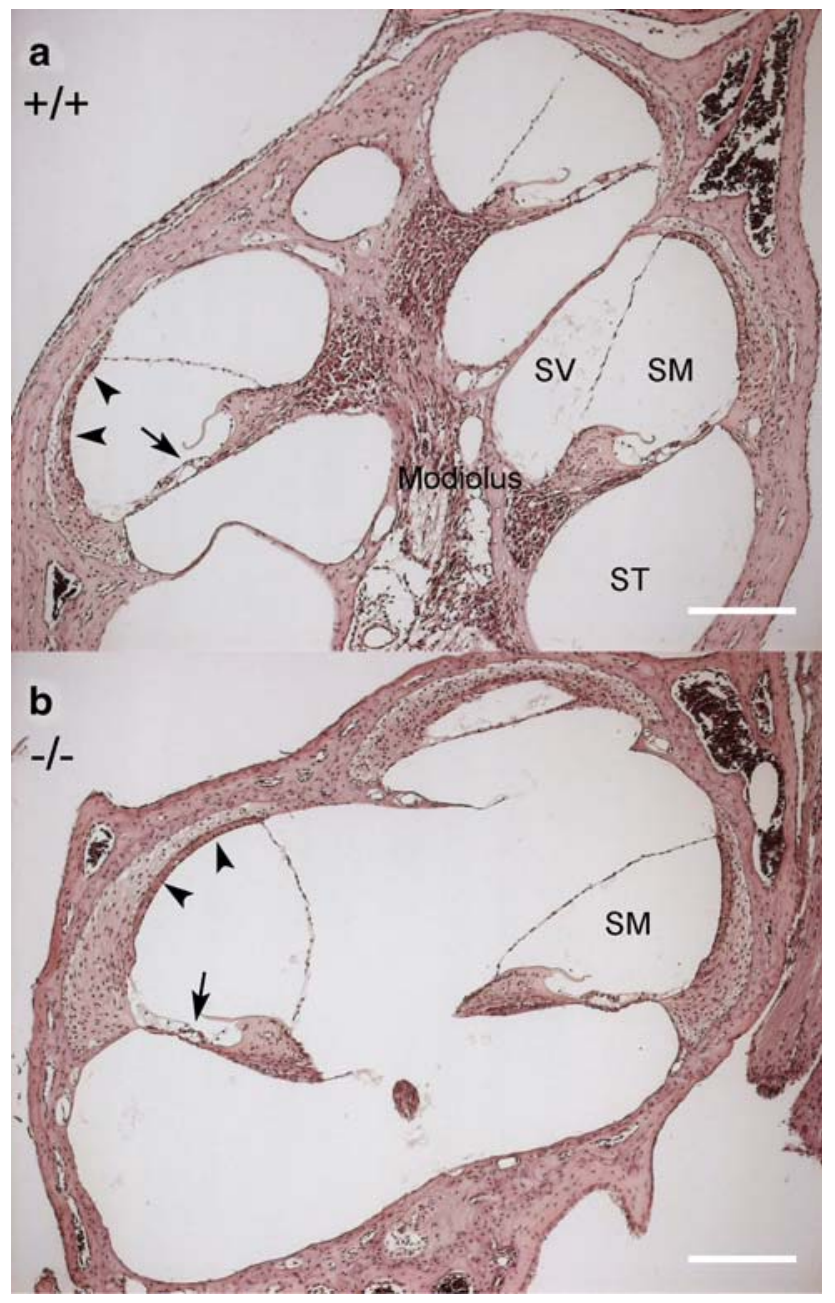

FIG. 6. Deficient modiolus and lack of spiral ganglion cells in the BETA2/NeuroD1 null cochlea. Mid-modiolar sections through paraffin-embedded cochleae were stained with $\mathrm{H}$ \& E. a The wildtype $(+/+)$ cochlea demonstrates normal architecture, including scala vestibuli ( $S V$ ), scala media $(S M)$, and scala tympani $(S T)$. The modiolus is filled with spiral ganglion cells. The organ of Corti (arrow) and the stria vascularis (arrowheads) are present. b The null $(-\digamma)$ cochlea has a deficient modiolus and there are no spiral ganglion cells. There are large connections within the central core of the cochlea connecting the cochlear turns. The scala media appears to be intact, however. The organ of Corti (arrow) and stria vascularis (arrowheads) also appear normal. Scale bar is $100 \mu \mathrm{m}$.

lation of phase lag at both the base and the apex. As a progressive phase delay is characteristic of traveling wave propagation (Patuzzi 1996), we conclude that traveling wave propagation is substantially faster with this malformation.

Preparation-induced artifacts due to mechanical loading or poor surface adhesion by the reflective bead (Khanna et al. 1998; Nuttall et al. 1991), having an opening in the cochlea (Cooper and Rhode 1996; Ulfendahl et al. 1991), and the innate resonance of the piezoelectric actuator may affect these data to some degree. However, the high degree of similarity between the responses we measured in control wildtype and heterozygote cochleae to normal responses reported in the literature argue against significant contamination. For example, the tuning curves from wild-type and heterozygous mice were comparable to tuning curves measured in vivo, such as in mice where the cochlear amplifier was absent due to tectorial membrane malformations (Legan et al. 2000; Legan et al. 2005). Additionally, the sharpness of the tuning curves we measured were similar to those described for other mammalian species in which the cochlear amplifier was inhibited (Cooper and Rhode 1995; Hemmert et al. 2000; Robles and

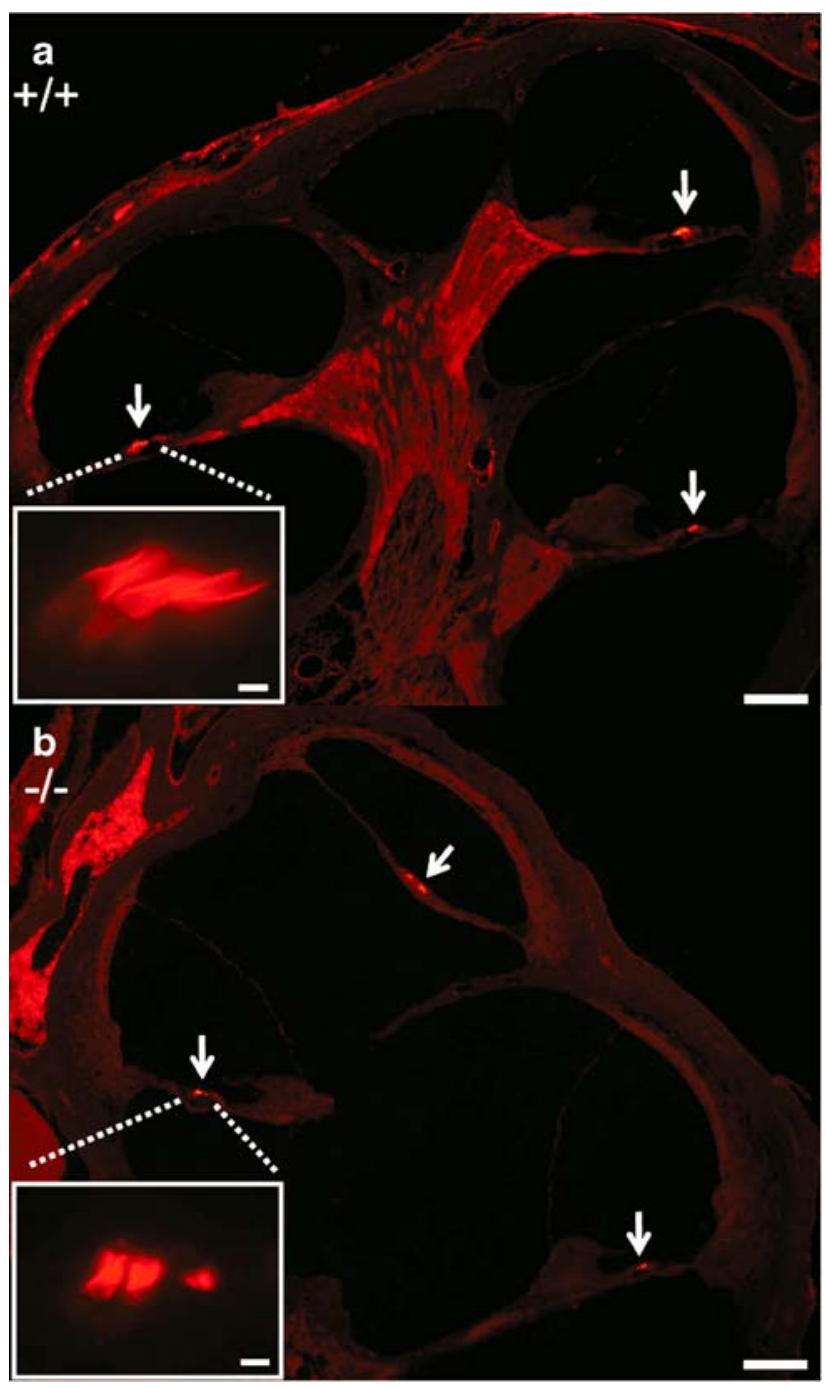

FIG. 7. Immunofluorescence localization of prestin. In both the wild-type $(\mathbf{a},+/+)$ and the null $(\mathbf{b},-/)$ cochleae, prestin was detected in the outer hair cells (arrows) in all turns of the cochleae. The insets are enlargements of the organ of Corti. Scale bar is $100 \mu \mathrm{m}$; insert scale bar is $10 \mu \mathrm{m}$. 


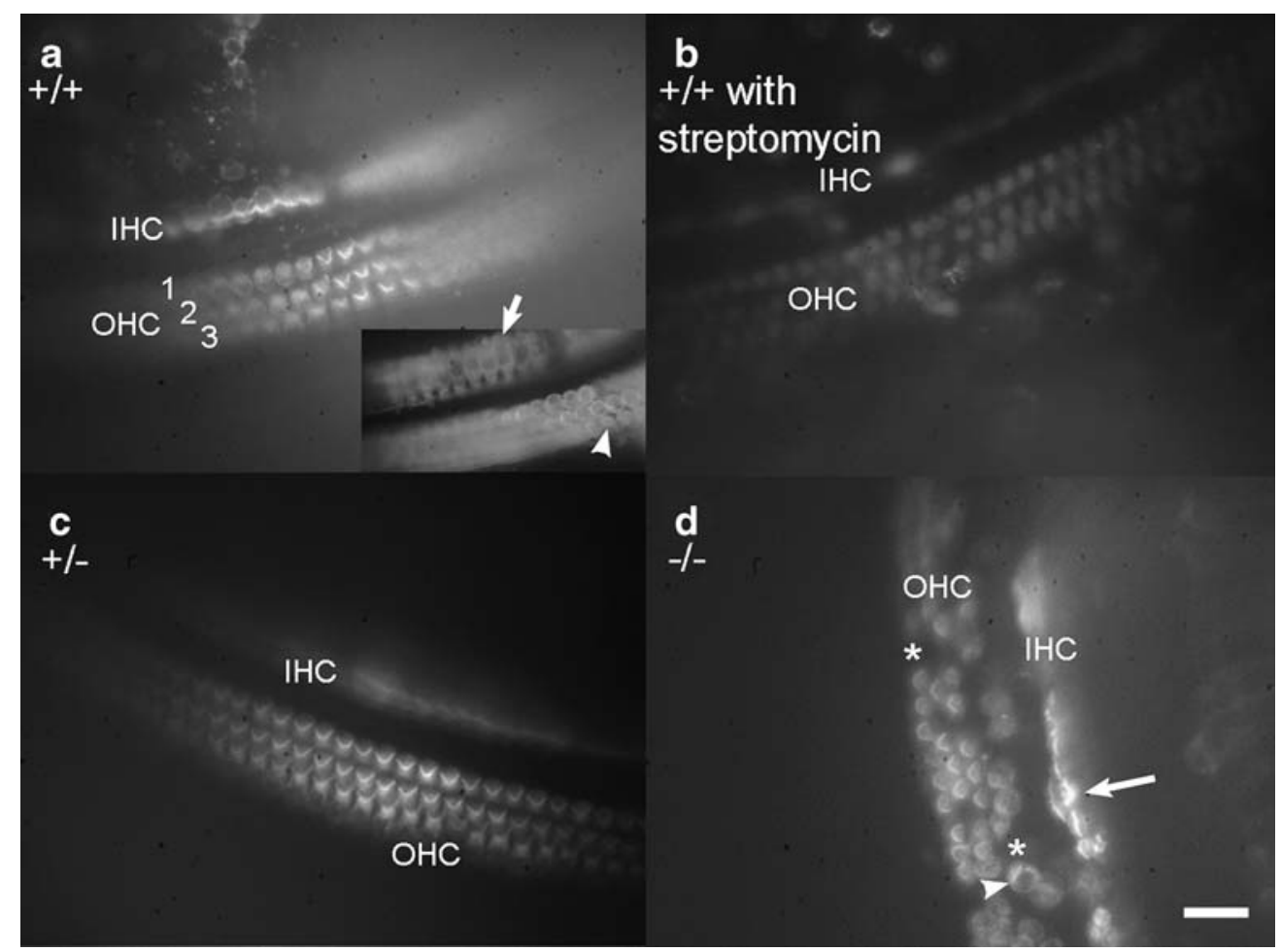

FIG. 8. FM 1-43 entry into hair cells through stereocilia. a Dye application to the wild-type $(+/+)$ organ of Corti demonstrated fluorescence primarily within the stereocilia of the single row of inner hair cells $(\mathrm{IHC})$ and of all three rows of outer hair cells $(\mathrm{OHC})$. A repeat image (inset) after an additional $90 \mathrm{~s}$ of washout reveals dye within the soma of the inner hair cells (arrow) and outer hair cells (arrowhead). b The pre-application of streptomycin inhibited the uptake of FM 1-43 dye, consistent with the blockage of mechano-

Ruggero 2001). Consistent with these findings, we found the expected accumulation of phase lag with increasing stimulus frequency (Geisler 1998; Robles and Ruggero 2001). Thus, we believe that the mechanics data reported herein reflect predominantly cochlear physiology and not artifact.

Why the incomplete partition malformation hastens the traveling wave is not obvious. Our current understanding of normal cochlear mechanics is that immediately after a movement of the stapes, a "fast" compression wave occurs because the fluid within the cochlea is essentially incompressible (Chadwick et al. 1980; Geisler 1998). Thus, the entire length of the cochlear partition is exposed to the sound pressure wave stimulus in a near-simultaneous fashion. However, the distributed variation in the innate mechanical properties of the cochlear partition produces a graded response pattern. This creates the appearance of a "slow" traveling wave (Ren 2002; Ruggero 1994; von Bekesy 1960). A key factor behind the production of a normal traveling wave is the concept that the impedance of the fluids within the cochlea are in series with the cochlear partition impedance. Thus, the fluid impedance sums from the oval window to the region of best frequency along the cochlear electrical transduction channels. $\mathbf{c}$ Hair cells in the heterozygous $\left(+/^{-}\right)$ mouse demonstrated normal dye uptake. $\mathbf{d}$ Hair cells in the null (-/-) mouse also demonstrated FM 1-43 dye uptake. Note the expected disorganization of the normal inner and outer hair cell regions of the organ of Corti, including a duplicated inner hair cell (arrow), missing outer hair cells (asterisk), and a rotated stereociliary bundle (arrowhead). Scale bar is $25 \mu \mathrm{m}$.

partition, and then back again to the round window. In this way, there is more fluid impedance influencing tuning at the cochlear apex than at the base. Historically, this is the main difference between the traveling wave theory of von Bekesy (von Bekesy 1960) and the earlier independent resonator theory of Helmholtz (Helmholtz and Ellis 1954).

One explanation of our data is that the incomplete partition between turns of the BETA2/NeuroD1 null mouse cochlea does not substantially alter the effect of the fast compression wave on the cochlear partition. Energy appears to be transmitted from the stapes to the cochlear partition because the peak tectorial membrane velocities were similar between the different genotypes. The converse is also true because all three genotypes demonstrated EEOAEs. Thus, even with the presence of an obvious shunt pathway from the oval to the round window and around the cochlear partition, the impedance of this shunt at acoustic frequencies is expected to be relatively high. However, the shunting may have more of an impact on the traveling wave in that perhaps there is less fluid impedance in series with the impedance of the cochlear partition (Fig. 9). In this way, the Helmholtz independent resonator theory 
may have some validity in a cochlea with an incomplete partition. Direct measurements of intracochlear fluid pressure in the null mouse may help to prove or disprove this concept (Olson 1999).

Another potential explanation for the reduced phase accumulation in the BETA2/NeuroD1 null is that the basilar membrane itself may be different in the mutants. Indeed, our findings are quite similar to that found in the base of the developing gerbil cochlea where the passive mechanics needed to sustain traveling wave propagation were found to progressively mature between postnatal days 14-20 (Overstreet et al. 2002). During this time period, the maximal phase lag accumulation progressively increased from about $180^{\circ}$ to the adult level of roughly $600-800^{\circ}$. Abnormal basilar membrane development, which may alter its stiffness, is likely associated with the shortened cochlear duct in the BETA2/NeuroD1 null mouse. However, the fact that the apex and the
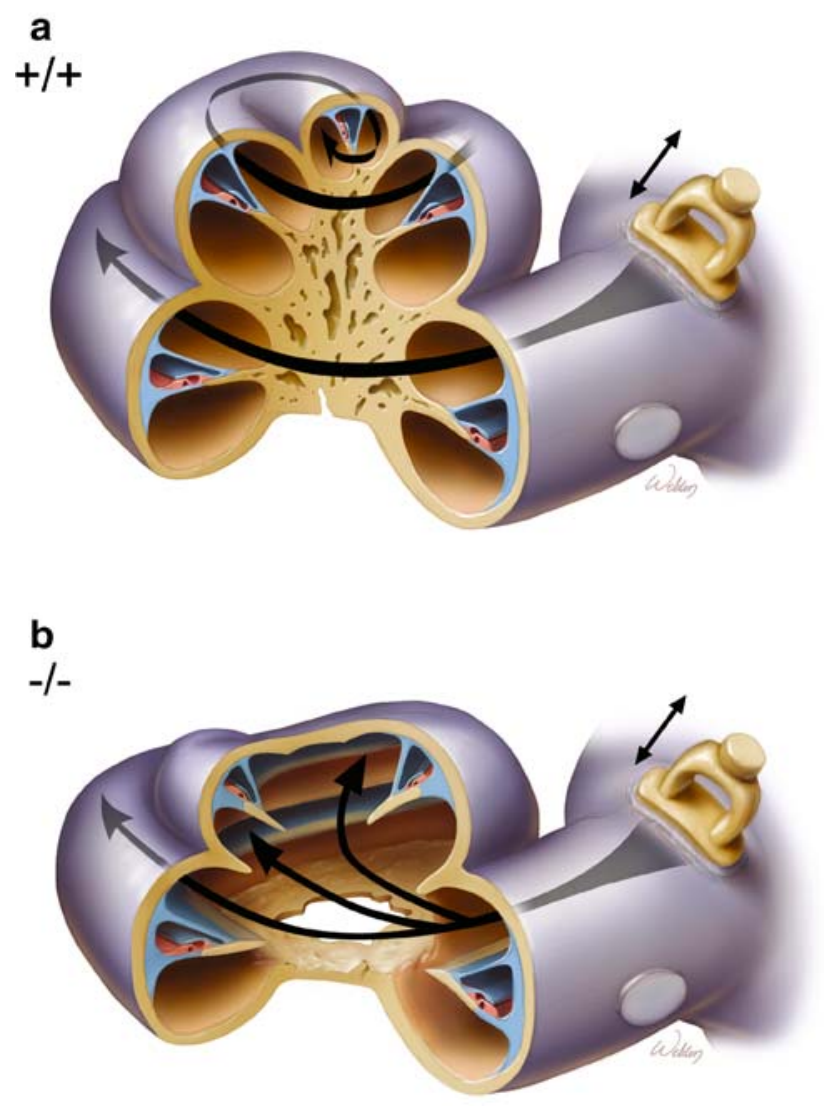

FIG. 9. Potential explanation for the altered traveling wave within the BETA2/NeuroD1 null cochlea. a In the wild-type $(+/+)$ mouse, the fluid impedance of the cochlear duct is summed along the length of the cochlear duct to the area of the cochlear partition tuned to the stimulus frequency. b In this rendition of the null $(-/)$ mouse cochlea, the modiolus is drawn as being severely deficient such that the fluid impedance is not summed in series, and instead the sound pressure wave is shunted across cochlear turns. base are tonotopically tuned to different, but appropriate, resonant frequencies at least suggests that there are regional variations in its physical properties.

While we consider these two explanations to be reasonable interpretations of our data, other possibilities should be considered. Recent modeling studies suggest that the cochlear coiling can impact cochlear micromechanics, particularly at the apex, by redistributing energy wave density (Cai et al. 2005; Cai et al. 2004; Manoussaki et al. 2006). However, the effect of the altered cochlear geometry of the BETA2/NeuroD1 null in these models is unknown. Finally, although the cochlear partition of the BETA2/NeuroD1 null is firmly fixed along its lateral edge (as in the wild-type), perhaps its medial edge is not as firmly fixed and causes abnormal radial motion to occur. Our measures of vertical motion would not detect this type of activity.

\section{The reduced endocochlear potential}

The BETA2/NeuroD1 null mouse has severe hearing loss because of the lack of spiral ganglion cells and our ABR results confirm previous reports (Kim et al. 2001; Liu et al. 2000a). However, the nearly 100-fold reduction in CM magnitude in null mice is also consistent with a more proximal defect, namely, the reduction in the endocochlear potential and the reduction in numbers and the disorganization of the hair cells.

The reason for the reduced endocochlear potential is unknown. However, there are previous reports of mutant mice with an endocochlear potential of zero or close to zero (Schrott et al. 1990; Steel and Barkway 1989; Steel et al. 1987). This appears to occur in mice with neural crest defects and reduced melanocyte counts within the stria vascularis, although a recent paper argues against the theory that melanin production is important to production of the endocochlear potential (Ohlemiller 2006; Ohlemiller et al. 2006). While light microscopy did not demonstrate any major anatomic defects in the BETA2/NeuroD1 null stria vascularis (Fig. 6), a specific assessment for the presence or number of melanin-containing cells was not performed. Certainly, the BETA2/NeuroD1 mutation affects neural development and cell migration, and thus, the mutation itself may be implicated in this pathophysiologic process.

Another possibility is that the anatomy of the cochlear dysplasia could lead to a reduced endocochlear potential. It is conceivable that the lack of or degeneration of modiolar precursors during development could create cracks in scala media, connecting the endolymph with the perilymph. Additionally, because the intracranial, sub-arachnoid space connects directly to the interior of the cochlea 
with this malformation, changes in intracranial pressure during straining could potentially damage the intracochlear structures. A classic clinical scenario in patients with cochlear malformations is that subtle head trauma causes a sudden, substantial sensorineural hearing loss. This has been hypothesized to represent rupture of the membranes of the inner ear (Cremers et al. 1998; Jackler and De La Cruz 1989; Stinckens et al. 2001).

\section{Reverse transduction in the mutant mouse}

Laser doppler vibrometry measures indicate that there are movements of the tectorial membrane in response to stapes displacement in the BETA2/ NeuroD1 null. However, this experimental paradigm does not permit an assessment of the impact of these movements on the hair cells. An indirect measure of this, the cochlear microphonic, could not be studied because of the reduced endocochlear potential. Another way to test the connection between outer hair cells and cochlear partition movements is to study reverse transduction. Indeed, electrically evoked otoacoustic emissions could be measured, suggesting that the movements of the cochlear partition could be evoked by an electric field in the BETA2/NeuroD1 null.

While the exact site from which the movements originated was not assessed in this study, the most likely source of force generation would be from outer hair cells (Halsey et al. 2005; Liberman et al. 2004). Force generation by outer hair cell somatic electromotility and/or stereociliary motility within the normal organ of Corti in response to electrical stimuli is called reverse transduction, and these processes have been postulated to underlie the cochlear amplifier (Fettiplace and Hackney 2006). In order for somatic electromotility to function normally, the prestin protein must be present in the lateral wall of outer hair cells (Liberman et al. 2002; Zheng et al. 2000). Our immunolabeling in the BETA2/NeuroD1 null is consistent with this, however subtle regional differences of prestin expression between outer hair cells of wild-type and null mice might not have been detected. In order for stereociliary motility to be functional, hair cell mechanoelectrical transduction channels must be functional. We showed that hair cells from null mice permit FM 1-43 entry in a fashion similar to that of hair cells from wild-type and heterozygous mice. However, it is important to note that normal FM 1-43 dye staining does not prove that mechanoelectrical transduction is normal. Direct measurements of somatic electromotility and transduction currents under whole-cell voltage-clamp are indicated to definitively assess this issue, but are beyond the scope of the present work.
One reason why electrically evoked otoacoustic emissions were lower in null mice compared to wildtype mice is likely related to the hair cell misalignment and the reduced numbers of outer hair cells. Fewer hair cells in the base of the cochlea could certainly explain the larger differences at higher frequencies. Future studies to quantify hair cell numbers along the length of the cochlear duct would be needed to assess this concept. Another possibility is that null mutant outer hair cells are shorter than wildtype or heterozygote outer hair cells, and the amplitude of electromotility depends on cell length (Dallos et al. 1993). A third reason is that the biomechanics of the cochlear partition as a whole are likely to be different in the null mouse. It is also possible that the electrical field generated passive movements of the tectorial membrane or basilar membrane directly, rather than outer hair cell force production. Even so, the fact that movement of the cochlear partition in the null mouse can elicit sound emission from the ear confirms the reciprocity between movements of the cochlear partition and movements of the stapes footplate in this dysplastic cochlea.

\section{Normal cochlear function in heterozygous mice}

Lastly, we found that the ABR and DPOAE thresholds of BETA2/NeuroD1 heterozygous mice are normal. A possible explanation for why we did not observe a difference between the cochlear function in wild-type and heterozygous mice in our study, as compared to the partial hearing loss found in the original ABR recordings by Liu et al. (2000a) is genetic drift. The mice in this study were from F3 and F4 generations, while the mice in the previous study were F1 and F2 generations. It is possible that a mild difference in hearing may have been lost as breeding modified the genetic background of the mice. However, it is also possible that the original $15 \mathrm{~dB}$ threshold shift found in heterozygous mice measured before was not accurate. The ABR data presented herein were collected using frequency specific stimuli, permitting a more refined and precise analysis of cochlear function than the previously used click stimuli recordings. It should be noted that our ABR and DPOAE data confirm each other in that neither demonstrated differences between wild-type and heterozygous mice. Additionally, our results correlate with the fact that wild-type and heterozygous cochleae are morphologically identical.

\section{Potential clinical implications}

The cochlear dysplasia found in the BETA2/NeuroD1 null mouse has many similarities with congenital cochlear malformations found in humans. One of 
the most common findings is Mondini dysplasia, more precisely termed the incomplete partition malformation. Patients with an incomplete partition malformation commonly have mild-to-moderate sensorineural hearing loss that often progresses to deafness (Bamiou et al. 1999; Coticchia et al. 2006). In this disorder, the cochlea is shorter than normal (only 1.5 instead of the normal 2.5 turns in humans) and its central modiolus is thin or missing (Schuknecht 1993). However, the auditory nerve is typically present. It is possible that progressive loss of the endocochlear potential may in part explain why humans with an incomplete partition malformation have progressive hearing loss.

Additionally, if these patients also have reduced phase accumulation, the delays associated with normal traveling wave propagation would not be present. This may adversely impact the central nervous system's ability to analyze complex signals, and would likely manifest as reduced speech discrimination in noise. If so, a hearing aid that could simulate a traveling wave by delaying low-frequency sounds relative to high-frequency sounds may provide clinical benefit.

\section{ACKNOWLEDGEMENT}

The authors wish to thank William E. Brownell, Ph.D., Ruth Anne Eatock, Ph.D., and Robert Raphael, Ph.D. for helpful advice, and Haiying Liu, Wen Chen, and Xue-Fei for technical support. The artwork is by Scott Weldon. This project was funded by NIH grant DC006671 (to JSO) and DC04585 (to FAP).

\section{REFERENCES}

Bamiou DE, Sayy L, O’Mahoney C, Phelps P, Sirimanna T. Unilateral sensorineural hearing loss and its aetiology in childhood: the contribution of computerised tomography in aetiological diagnosis and management. Int J Pediatr Otorhinolaryngol 51(2):91-99, 1999.

Brownell WE, Bader CR, Bertrand D, de Ribaupierre Y. Evoked mechanical responses of isolated cochlear outer hair cells. Science 227(4683):194-196, 1985.

Cai H, Manoussaki D, Chadwick R. Effects of coiling on the micromechanics of the mammalian cochlea. J R Soc Interface 2(4):341-348, 2005.

Cai H, Shoelson B, Chadwick RS. Evidence of tectorial membrane radial motion in a propagating mode of a complex cochlear model. Proc Natl Acad Sci USA 101(16):6243-6248, 2004.

Chadwick RS, Fourney ME, Neiswander P. Modes and waves in a cochlear model. Hear Res 2(3-4):475-483, 1980.

Chan DK, Hudspeth AJ. Ca(2+) current-driven nonlinear amplification by the mammalian cochlea in vitro. Nat Neurosci 8(2):149-155, 2005.

Cheatham MA, Dallos P. Two-tone interactions in the cochlear microphonic. Hear Res 8(1):29-48, 1982.
Cheatham MA, Dallos P. Low-frequency modulation of inner hair cell and organ of Corti responses in the guinea pig cochlea. Hear Res 108(1-2):191-212, 1997.

Cody AR, Johnstone BM. Single auditory neuron response during acute acoustic trauma. Hear Res 3(1):3-16, 1980.

Cooper NP, Rhode WS. Nonlinear mechanics at the apex of the guinea-pig cochlea. Hear Res 82(2):225-243, 1995.

COOPER NP, RHODE WS. Fast traveling waves, slow traveling waves and their interactions in experimental studies of cochlear mechanics. Auditory Neuroscience 2:289-299, 1996.

Coticchia JM, Gokhale A, Waltonen J, Sumer B. Characteristics of sensorineural hearing loss in children with inner ear anomalies. Am J Otolaryngol 27(1):33-38, 2006.

Cremers CW, Admiraal rJ, Huygen Pl, Bolder C, Everett la, Joosten FB, Green ED, van Camp G, Otten BJ. Progressive hearing loss, hypoplasia of the cochlea and widened vestibular aqueducts are very common features in Pendred's syndrome. Int J Pediatr Otorhinolaryngol 45(2):113-123, 1998.

DaLLos P. Electrical correlates of mechanical events in the cochlea. Audiology 14(5-6):408-418, 1975.

Dallos P, Hallworth R, Evans BN. Theory of electrically driven shape changes of cochlear outer hair cells. J Neurophysiol $70(1): 299-323,1993$.

Davis H. An active process in cochlear mechanics. Hear Res 9(1):79-90, 1983.

FetTiPlaCe R, HACKNey CM. The sensory and motor roles of auditory hair cells. Nat Rev Neurosci 7(1):19-29, 2006.

Gale JE, Marcotti W, Kennedy HJ, Kros CJ, Richardson GP. FM1-43 dye behaves as a permeant blocker of the hair-cell mechanotransducer channel. J Neurosci 21(18):7013-7025, 2001.

GEISLER CD. From sound to synapse: physiology of the mammalian ear. New York: Oxford University Press. xiv, 381 p, 1998.

Griesinger CB, Richards CD, Ashmore JF. Fm1-43 reveals membrane recycling in adult inner hair cells of the mammalian cochlea. J Neurosci 22(10):3939-3952, 2002

Griesinger CB, Richards CD, Ashmore JF. Apical endocytosis in outer hair cells of the mammalian cochlea. Eur J Neurosci 20(1):41-50, 2004.

GRIESINGER CB, Richards CD, Ashmore JF. Fast vesicle replenishment allows indefatigable signalling at the first auditory synapse. Nature 435(7039):212-215, 2005.

Gummer AW, Hemmert W, Zenner HP. Resonant tectorial membrane motion in the inner ear: its crucial role in frequency tuning. Proc Natl Acad Sci USA 93(16):8727-8732, 1996.

Gummer AW, Meyer J, Frank G, Scherer MP, Preyer S. Mechanical transduction in outer hair cells. Audiol Neurootol 7(1):13-16, 2002.

Halsey K, Fegelman K, Raphael Y, Grosh K, Dolan DF. Long-term effects of acoustic trauma on electrically evoked otoacoustic emission. J Assoc Res Otolaryngol 6(4):324-340, 2005.

Helmholtz Hv, Ellis AJ. On the sensations of tone as a physiological basis for the theory of music. New York,: Dover Publications. xix, 576 p., 1954.

Hemmert W, Zenner H, Gummer AW. Characteristics of the travelling wave in the low-frequency region of a temporal-bone preparation of the guinea-pig cochlea. Hear Res 142(1-2):184202, 2000.

Hubbard AE, Mountain DC. Haircell forward and reverse transduction: differential suppression and enhancement. Hear Res 43(2-3):269-272, 1990.

JaCKLER RK, De La CRUZ A. The large vestibular aqueduct syndrome. Laryngoscope 99(12):1238-1242; discussion 1242-1243, 1989.

JACKLER RK, LuXFORd WM, House WF. Congenital malformations of the inner ear: a classification based on embryogenesis. Laryngoscope 97(3 Pt 2 Suppl 40):2-14, 1987.

JiA S, HE DZ. Motility-associated hair-bundle motion in mammalian outer hair cells. Nat Neurosci 8(8):1028-1034, 2005. 
Kaneko T, Harasztosi C, Mack AF, Gummer AW. Membrane traffic in outer hair cells of the adult mammalian cochlea. Eur J Neurosci 23(10):2712-2722, 2006.

Kennedy HJ, Evans MG, Crawford AC, Fettiplace R. Depolarization of cochlear outer hair cells evokes active hair bundle motion by two mechanisms. J Neurosci 26(10):2757-2766, 2006.

Khanna SM, Ulfendahl M, Steele CR. Vibration of reflective beads placed on the basilar membrane. Hear Res 116(1-2):71-85, 1998.

Kim WY, Fritzsch B, Serls A, Bakel LA, Huang EJ, Reichardt LF, BARTh DS, LeE JE. NeuroD-null mice are deaf due to a severe loss of the inner ear sensory neurons during development. Development 128(3):417-426, 2001.

Lee Je, Hollenberg SM, Snider L, Turner DL, Lipnick N, Weintraub H. Conversion of Xenopus ectoderm into neurons by NeuroD, a basic helix-loop-helix protein. Science 268(5212):836-844, 1995.

Legan PK, Lukashina VA, Goodyear RJ, Kossi M, Russell IJ, RICHARDSON GP. A targeted deletion in alpha-tectorin reveals that the tectorial membrane is required for the gain and timing of cochlear feedback. Neuron 28(1):273-285, 2000.

Legan PK, Lukashkina VA, Goodyear RJ, Lukashin AN, Verhoeven K, Van Camp G, Russell IJ, Richardson GP. A deafness mutation isolates a second role for the tectorial membrane in hearing. Nat Neurosci 8(8):1035-1042, 2005.

Liberman MC. The cochlear frequency map for the cat: labeling auditory-nerve fibers of known characteristic frequency. J Acoust Soc Am 72(5):1441-1449, 1982.

Liberman MC, Gao J, He DZ, Wu X, Jia S, Zuo J. Prestin is required for electromotility of the outer hair cell and for the cochlear amplifier. Nature 419(6904):300-304, 2002.

Liberman MC, Zuo J, Guinan JJ, JR. Otoacoustic emissions without somatic motility: can stereocilia mechanics drive the mammalian cochlea? J Acoust Soc Am 116(3):1649-1655, 2004.

Liu M, Pereira FA, Price SD, Chu MJ, Shope C, Himes D, Eatock RA, Brownell WE, Lysakowski A, Tsai MJ. Essential role of BETA2/ NeuroD1 in development of the vestibular and auditory systems. Genes Dev 14(22):2839-2854, 2000a.

Liu M, Pleasure SJ, Collins Ae, Noebels Jl, Naya FJ, Tsai MJ, LowENSTEIN DH. Loss of BETA2/NeuroD leads to malformation of the dentate gyrus and epilepsy. Proc Natl Acad Sci USA 97(2):865-870, 2000b.

Mammano F, Ashmore JF. Reverse transduction measured in the isolated cochlea by laser Michelson interferometry. Nature 365(6449):838-841, 1993.

Mammano F, Ashmore JF. A laser interferometer for sub-nanometre measurements in the cochlea. J Neurosci Methods 60(1-2):8994, 1995 .

Manoussaki D, Dimitriadis EK, Chadwick RS. Cochlea's graded curvature effect on low frequency waves. Phys Rev Lett 96(8):088701, 2006.

Meyers JR, MacDonald RB, Duggan A, Lenzi D, Standaert DG, CoRWIN JT, CoRey DP. Lighting up the senses: FM1-43 loading of sensory cells through nonselective ion channels. J Neurosci 23(10):4054-4065, 2003.

Morioka I, Reuter G, Reiss P, Gummer AW, Hemmert W, Zenner HP. Sound-induced displacement responses in the plane of the organ of Corti in the isolated guinea-pig cochlea. Hear Res 83(1-2):142-150, 1995.

Morsli H, Choo D, Ryan A, Johnson R, Wu DK. Development of the mouse inner ear and origin of its sensory organs. J Neurosci 18(9):3327-3335, 1998.

Mountain DC, HubBard AE. Rapid force production in the cochlea. Hear Res 42(2-3):195-202, 1989

Muller M, von Hunerbein K, Hoidis S, Smolders JW. A physiological place-frequency map of the cochlea in the $\mathrm{CBA} / \mathrm{J}$ mouse. Hear Res 202(1-2):63-73, 2005.
Naya FJ, Stellrecht CM, Tsai MJ. Tissue-specific regulation of the insulin gene by a novel basic helix-loop-helix transcription factor. Genes Dev 9(8):1009-1019, 1995.

Nowotny M, Gummer AW. Nanomechanics of the subtectorial space caused by electromechanics of cochlear outer hair cells. Proc Natl Acad Sci USA 103(7):2120-2125, 2006.

Nuttall AL, Dolan DF, Avinash G. Laser Doppler velocimetry of basilar membrane vibration. Hear Res 51(2):203-213, 1991.

Nuttall AL, Zheng J, Ren T, de Boer E. Electrically evoked otoacoustic emissions from apical and basal perilymphatic electrode positions in the guinea pig cochlea. Hear Res 152(1-2):77-89, 2001.

Oghalai JS. Chlorpromazine inhibits cochlear function in guinea pigs. Hear Res 198(1-2):59-68, 2004.

OHLEMILLER KK. Contributions of mouse models to understanding of age- and noise-related hearing loss. Brain Res 1091(1):89102, 2006.

Ohlemiller KK, Lett JM, GAGNon PM. Cellular correlates of agerelated endocochlear potential reduction in a mouse model. Hear Res 220:10-26, 2006.

Olson ES. Direct measurement of intra-cochlear pressure waves. Nature 402(6761):526-529, 1999.

Ou HC, HARDING GW, BoHNE BA. An anatomically based frequencyplace map for the mouse cochlea. Hear Res 145(1-2):123-129, 2000.

Overstreet EH, 3Rd, Temchin AN, Ruggero MA. Passive basilar membrane vibrations in gerbil neonates: mechanical bases of cochlear maturation. J Physiol 545(Pt 1):279-288, 2002.

PATuzZi R. Cochlear micromechanics and macromechanics. In: Dallos P, Popper AN, Fay RR (eds) The Cochlea: Springer Handbook Of Auditory Research; v. 8. New York: Springer. p xii, 551 p., 1996.

Patuzzi R, Moleirinho A. Automatic monitoring of mechanoelectrical transduction in the guinea pig cochlea. Hear Res 125(1-2):1-16, 1998.

Patuzzi RB, Yates GK, Johnstone BM. The origin of the lowfrequency microphonic in the first cochlear turn of guinea-pig. Hear Res 39(1-2):177-188, 1989.

Paylor R, Glaser B, Mupo A, Ataliotis P, Spencer C, Sobotka A, Sparks C, Choi CH, Oghalai J, Curran S, Murphy KC, Monks S, Williams N, O’Donovan MC, Owen MJ, Scambler PJ, Lindsay E. Tbx1 haploinsufficiency is linked to behavioral disorders in mice and humans: implications for $22 \mathrm{q} 11$ deletion syndrome. Proc Natl Acad Sci USA 103(20):7729-7734, 2006.

REN T. Longitudinal pattern of basilar membrane vibration in the sensitive cochlea. Proc Natl Acad Sci USA 99(26):17101-17106, 2002.

Ren T, Nuttall AL. Extracochlear electrically evoked otoacoustic emissions: a model for in vivo assessment of outer hair cell electromotility. Hear Res 92(1-2):178-183, 1995.

Ren T, Nuttall AL. Fine structure and multicomponents of the electrically evoked otoacoustic emission in gerbil. Hear Res 143(1-2):58-68, 2000.

RHODE WS. Observations of the vibration of the basilar membrane in squirrel monkeys using the Mossbauer technique. J Acoust Soc Am 49(4):Suppl 2:1218+, 1971.

Robles L, Ruggero MA. Mechanics of the mammalian cochlea. Physiol Rev 81(3):1305-1352, 2001.

RUGGero MA. Cochlear delays and traveling waves: comments on 'Experimental look at cochlear mechanics'. Audiology 33(3):131-142, 1994.

RugGero MA, Rich NC. Furosemide alters organ of corti mechanics: evidence for feedback of outer hair cells upon the basilar membrane. J Neurosci 11(4):1057-1067, 1991.

Schrott A, Melichar I, Popelar J, Syka J. Deterioration of hearing function in mice with neural crest defect. Hear Res 46(1-2):17, 1990 . 
Schuknecht HF. Pathology of the ear. Philadelphia: Lea \& Febiger. xv, 672 p, 1993.

Steel KP, Barkway C. Another role for melanocytes: their importance for normal stria vascularis development in the mammalian inner ear. Development 107(3):453-463, 1989.

Steel KP, Barkway C, Bock GR. Strial dysfunction in mice with cochleo-saccular abnormalities. Hear Res 27(1):11-26, 1987.

Stinckens C, Huygen PL, Joosten FB, Van Camp G, Otten B, Cremers CW. Fluctuant, progressive hearing loss associated with Meniere like vertigo in three patients with the Pendred syndrome. Int J Pediatr Otorhinolaryngol 61(3):207-215, 2001.

Ulfendahl M, Khanna SM, Flock A. Effects of opening and resealing the cochlea on the mechanical response in the isolated temporal bone preparation. Hear Res 57(1):31-37, 1991.

von BeKEsy G. Experiments in hearing: McGraw-Hill, 1960.

Wenzel GI, Anvari B, Mazhar A, Pikkula B, Oghalai JS. Laser induced collagen remodeling and deposition within the basilar membrane of the mouse Cochlea. J Biomed Opt 12:021007, 2006.

Xue S, Mountain DC, Hubbard AE. Acoustic enhancement of electrically-evoked otoacoustic emissions reflects basilar membrane tuning: experiment results. Hear Res 70(1):121-126, 1993.

Zheng J, Shen W, He DZ, Long KB, Madison LD, Dallos P. Prestin is the motor protein of cochlear outer hair cells. Nature 405(6783):149-155, 2000. 